\title{
USO DE MÉTODOS ANALÍTICOS CONVENCIONADOS NO ESTUDO DA AUTENTICIDADE DO ÓLEO DE COPAÍBA
}

\author{
Antônio Francisco Fernandes de Vasconcelos e Oswaldo Espirito Santo Godinho*
}

Departamento de Química e Tecnologia Química, Centro de Ciências Exatas e Tecnologia, Universidade Federal do Maranhão, Av. dos Portugueses, s/n, 65080-040 São Luis - MA

Recebido em 20/6/01; aceito em 3/6/02

\begin{abstract}
USE OF CLASSICAL ANALYTICAL METHODS TO INVESTIGATE THE AUTHENTICITY OF COPAIBA OIL. The acidity and ester index are suggested, as simple and cheap methods, adequate to be employed in the study of the authenticity of copaíba oil by small drugstores and export firms. The acidity index permits both the detection and the evaluation of the content of adulteration of copaíba oil. The ester index permits to know if the adulterant either contain ester compounds,as the case of fatty oils, or contain only non saponifiable compounds as is the case of ethyl alchool or mineral oil. The results of the aplication of the methods to eight commercial samples, of copaiba oil, where three samples were adultered, are coherent with those obtained by more sophisticated instrumental methods.
\end{abstract}

Keywords: copaiba oil authenticity control.

\section{INTRODUÇÃO}

O óleo de copaíba, extraído do tronco de árvores de diversas espécies do gênero Copaifera, é bastante empregado na medicina popular, principalmente no norte do Brasil ${ }^{1-3}$. Além de ser consumido na qualidade de componente de produtos, tais como pomadas e xaropes, é também muito consumido in natura, por administração oral ou aplicação tópica. Convém também não esquecer a importância da atividade comercial, através da exportação do óleo de copaíba para a indústria de cosméticos. Entretanto, como acontece em geral com os medicamentos fitoterápicos no Brasil, o óleo de copaíba não é submetido a um adequado controle de qualidade ${ }^{1}$.

O desenvolvimento de métodos analíticos, baseados no uso das técnicas da cromatografia gasosa de alta resolução (CGAR) e cromatografia gasosa de alta resolução acoplada à espectrometria de massa (CGAR-EM), para controle da autenticidade do óleo de copaíba foi descrita por Veiga Jr. et al. ${ }^{1}$.

Entretanto, observa-se a necessidade de métodos analíticos simples, para serem empregados em pequenos estabelecimentos comerciais, com poucos recursos laboratoriais. Isto é especialmente verdade no caso das pequenas empresas que exportam o produto para indústrias de cosméticos onde, muitas vezes, o preço do produto é aviltado devido a dificuldades de se comprovar a autenticidade do mesmo.

Nestes pequenos estabelecimentos, certas propriedades físicas da amostra, como a viscosidade ou mesmo a cor, têm sido utilizadas como critério de autenticidade do óleo de copaíba. De maneira análoga, a solubilidade da amostra em álcool absoluto tem sido empregada para indicar a ausência de adulteração do óleo de copaíba por óleos graxos ${ }^{4}$. Entretanto, como será discutido no decorrer deste trabalho, estes testes não são conclusivos, embora o teste da solubilidade em etanol possa ser útil se for utilizado em conjunto com outras observações.

Neste trabalho, investigou-se a determinação e a possível utilização de parâmetros analíticos simples, como os índices de acidez e de éster, na investigação da adulterações grosseiras do óleo de

*e-mail: oswaldogodinho@uol.com.br copaíba. Pretende-se fornecer subsídios para o estabelecimento de métodos de controle de qualidade do óleo de copaíba que possam ser utilizados por laboratórios com poucos recursos.

\section{PARTE EXPERIMENTAL}

\section{Amostras de óleo de copaíba}

A amostra de referência de óleo de copaíba foi obtida por incisão do tronco de espécie adulta de Copaífera langsdorffi (Copaíba Vermelha) no município de Buriticupu - MA. O óleo foi armazenado em frasco escuro e mantido hermeticamente fechado. No caso dos produtos comerciais escolheu-se aqueles que estavam dentro do prazo de validade, rotulados e hermeticamente fechados. Foram analisados produtos adquiridos em drogarias de São Luis - MA, provenientes dos seguintes laboratórios: Labomed (Castanhal-PA), Pharmus (Anápolis-GO); Pronatus (Belém-PA); Indústria Brasileira de Alimentos Naturais (Maracanau-CE); Pharmacon (ImperatrizMA); Botica do Amazonas (Manaus-AM). Empregou-se também duas amostras de óleo de copaíba, das quais uma foi adquirida na feira livre do Mercado Central (São Luis-MA) e outra na feira livre do João Paulo ( São Luis-MA). As amostras comerciais que constam das Tabelas 1 e 2 não são apresentadas em ordem alfabética, nem tem qualquer relação com a ordem das amostras aqui apresentadas.

\section{Índices de acidez e de éster}

As definições de índices de acidez e de éster utilizadas neste trabalho são as mesmas empregadas convencionalmente no estudo do controle de qualidade dos óleos graxos ${ }^{5}$.

Índice de acidez é a massa de hidróxido de potássio, em miligramas, gasta na neutralização dos ácidos livres presentes em um grama de amostra de óleo.

Índice de éster é definido como a massa de hidróxido de potássio, em miligramas, gasta na saponificação de um grama de amostra de óleo neutro. Nesta definição não está incluída a massa de hidróxido de potássio gasta na neutralização dos ácidos livres presentes na amostra de óleo. 
Tabela 1. Dados obtidos na determinação do índice de acidez de misturas de óleo de copaíba e óleo de soja e de misturas de óleo de copaíba e álcool etílico

\begin{tabular}{|c|c|c|c|}
\hline \multicolumn{2}{|c|}{$\begin{array}{l}\text { Misturas de óleo de copaíba e } \\
\text { óleo de soja }\end{array}$} & \multicolumn{2}{|c|}{$\begin{array}{l}\text { Misturas de óleo de copaíba e } \\
\text { álcool etílico }\end{array}$} \\
\hline $\begin{array}{l}\% \text { de óleo } \\
\text { de soja }\end{array}$ & $\begin{array}{l}\text { Índice de } \\
\text { acidez }^{2}\end{array}$ & $\begin{array}{c}\% \text { de álcool } \\
\text { etílico }^{1}\end{array}$ & $\begin{array}{l}\text { Índice de } \\
\text { acidez }^{2}\end{array}$ \\
\hline 0,0 & 81,4 & 0,0 & 81,4 \\
\hline 10,3 & 67,4 & 10,1 & 67,5 \\
\hline 22,0 & 58,4 & 18,8 & 55,6 \\
\hline 27,5 & 56,9 & 40,1 & 38,1 \\
\hline 74,0 & 20,9 & 49,4 & 36,3 \\
\hline 78,0 & 16,0 & 80,0 & 5,5 \\
\hline 100,0 & 0,6 & 100,0 & 0,0 \\
\hline
\end{tabular}

${ }^{1}$ Porcentagem em massa. ${ }^{2} \mathrm{mg}$ de $\mathrm{KOH} / \mathrm{g}$ de óleo.

Tabela 2. Dados obtidos para o índice de éster de misturas de óleo de copaíba e óleo de soja e de misturas de óleo de copaíba e álcool etílico

\begin{tabular}{|c|c|c|c|}
\hline \multicolumn{2}{|c|}{$\begin{array}{l}\text { Misturas de óleo de copaíba e } \\
\text { óleo de soja }\end{array}$} & \multicolumn{2}{|c|}{$\begin{array}{l}\text { Misturas de óleo de copaíba } \\
\text { álcool etílico }\end{array}$} \\
\hline $\begin{array}{l}\% \text { de óleo } \\
\text { de soja }{ }^{1}\end{array}$ & $\begin{array}{l}\text { Índice de } \\
\text { éster }^{2}\end{array}$ & $\begin{array}{c}\% \text { de álcool } \\
\text { etílico }^{1}\end{array}$ & $\begin{array}{l}\text { Índice de } \\
\text { éster }^{2}\end{array}$ \\
\hline 0,0 & 22,7 & 0,0 & 22,7 \\
\hline 10,3 & 25,2 & 10,1 & 16,0 \\
\hline 22,0 & 43,5 & 18,8 & 13,6 \\
\hline 27,5 & 55,5 & 40,1 & 6,8 \\
\hline 74,0 & 129,0 & 49,4 & 5,9 \\
\hline 78,0 & 136,2 & 80,0 & 1,5 \\
\hline 100,0 & 170,3 & 100,0 & 0,0 \\
\hline
\end{tabular}

$\overline{{ }^{1} \text { Porcentagem em massa. }{ }^{2} \mathrm{mg} \mathrm{KOH} \text { (gasto na saponificação)/g de }}$ óleo.

\section{Procedimento para determinação do índice de acidez $^{5}$}

Pesou-se cerca de $2 \mathrm{~g}$ do óleo em um erlemeyer de $125 \mathrm{~mL}$ e a seguir adicionou-se $25 \mathrm{ml}$ da mistura eter etílico : álcool etílico (2:1) acompanhado de agitação. Adicionou-se a seguir 2 gotas de solução alcoólica de fenolftaleina e titulou-se com solução $0,1 \mathrm{~N}$ de hidróxido de sódio até que a solução passasse de incolor para uma coloração rósea.

O índice de acidez é calculado pela equação;

$\mathrm{IA}=\frac{\mathrm{VN} .56,1}{\mathrm{~m}}$

em que $\mathrm{V}$ é o volume de solução de $\mathrm{NaOH}$ gasto na titulação em mililitros, $\mathrm{N}$ é a normalidade da solução e $\mathrm{m}$ é a massa da amostra em gramas.

\section{Procedimento para a determinação do índice de éster ${ }^{5}$}

Pesou-se cerca de $2 \mathrm{~g}$ de óleo em um erlemeyer, adicionou-se cerca de $5 \mathrm{~mL}$ de álcool etilíco com agitação e, a seguir, 2 gotas de solução alcoólica de fenolftaleina $1 \%$ e titulou-se com solução $0,1 \mathrm{~N}$ de hidróxido de sódio até que ocorresse a mudança da cor da solução de incolor para rósea. À solução resultante da titulação adicionou-se $20 \mathrm{~mL}$ de solução de hidróxido de potássio $4 \%$ com uma bureta. Adaptou-se o erlemeyer a um condensador de refluxo e aqueceu-se a ebulição em banho-maria por 30 min. Após resfriamento da solução, adicionou-se 2 gotas de solução alcoólica $1 \%$ de fenolftaleina, e titulou-se com uma solução $0,5 \mathrm{~N}$ de $\mathrm{HCl}$ até que ocorresse a mudança de cor da solução de rósea para incolor. Realizou-se uma titulação em branco onde estavam presentes todos os reagentes com exceção da amostra de óleo.A diferença entre os dois volumes de solução de $\mathrm{HCl}$ está relacionada com a quantidade hidróxido de potássio gasto na saponificação dos ésteres presentes no óleo.

O índice de éster é calculado pela equação:

$\mathrm{IE}=\underline{\mathrm{VN} .56,1}$

em que $\mathrm{V}$ representa a diferença entre os volumes de solução de $\mathrm{HCl}$ gastos na titulação da amostra e do branco em mililitros, N é a normalidade da solução de $\mathrm{HCl}$ e m é a massa de amostra de óleo em grama.

\section{Procedimento sugerido para a detecção e avaliação de adulteração do óleo de copaíba}

Este procedimento envolve inicialmente as determinações dos índices de acidez e de éster da amostra considerada. Se o valor do índice de acidez obtido for maior que $80 \mathrm{mg} \mathrm{KOH} / \mathrm{g}$ a amostra é considerada autêntica, se o valor deste índice for menor que $80 \mathrm{mg}$ $\mathrm{KOH} / \mathrm{g}$ admite-se tratar de amostra adulterada. Se o índice de acidez for menor que $80 \mathrm{mg} \mathrm{KOH} / \mathrm{g}$ e o índice de éster maior que $23 \mathrm{mg}$ $\mathrm{KOH} / \mathrm{g}$ considera-se o adulterante como sendo constituído de óleo graxo. Por outro lado, se o índice de acidez da amostra for menor que $80 \mathrm{mg} \mathrm{KOH} / \mathrm{g}$ e o índice de éster for menor que $23 \mathrm{mg} \mathrm{KOH} / \mathrm{g}$ admite-se que o adultrante é constituído de material não saponificável como óleo mineral ou álcool etílico.

A concentração aproximada do adulterante nas amostras adulteradas pode ser calculada pela equação:

$\% \mathrm{AD}=(1-\mathrm{IA} / 85) \cdot 100$

em que $\% \mathrm{AD}$ representa a porcentagem do adulterante na amostra e IA é o valor do índice de acidez da mesma.

\section{RESULTADOS E DISCUSSÃO}

De acordo com informações de vendedores de óleo de copaíba, óleos graxos e álcool etílico seriam os produtos mais prováveis de serem encontrados como aditivos do óleo de copaíba. Em vista disto, procurou-se investigar a influência da composição de misturas: óleo de copaíba-óleo graxo (utilizou-se óleo de soja) e óleo de copaíba-álcool etílico sobre os valores dos índices de acidez e de éster das referidas misturas.

Índice de acidez de misturas de óleo de copaíba e óleo de soja e de misturas de óleo de copaíba e álcool etílico

Podem-se deduzir equações que relacionam o índice de acidez das misturas óleo de copaíba-óleo de soja e óleo de copaíba-álcool etílico com a composição das mesmas. No caso da mistura óleo de copaíba - óleo de soja a referida equação toma a seguinte forma:

$\mathrm{IA}=\mathrm{IAc}+\frac{(\mathrm{IAs}-\mathrm{IAc})(\% \mathrm{~S})}{100}$

em que IA representa o índice de acidez de uma dada mistura de óleo de copaíba e óleo de soja e \%S representa a porcentagem de óleo de soja na referida mistura. IAs e IAc representam os índices de acidez 
dos óleos de soja e de copaíba "puros", respectivamente. A equação (4) mostra que há uma relação linear ente o índice de acidez da mistura e a porcentagem de óleo de soja na mesma. Neste caso IAc representa o coeficiente linear e a expressão (IAs - IAc)/100 representa o coeficiente angular da reta.

No caso da mistura óleo de copaíba e álcool etílico a equação (4) toma a seguinte forma:

$$
\mathrm{IA}=\mathrm{IAc}+\frac{(\mathrm{IAa}-\mathrm{IAc})(\% \mathrm{~A})}{100}
$$

Na equação (5) IA representa o índice de acidez da mistura óleo de copaíba - álcool etílico e \%A representa a porcentagem de álcool etílico na mistura. IAc e IAa representam os índices de acidez do óleo de copaíba e do álcool etílico "puros", respectivamente. A equação (5) é a equação de uma reta que apresenta IAc como coeficiente linear e (IAa -IAc)/100 como coeficiente angular.

Para testar a validade das equações (4) e (5) determinaram-se experimentalmente os valores do índice de acidez de misturas de composição variável de óleo de copaíba - óleo de soja e de óleo de copaíba - álcool etílico. Os resultados obtidos são mostrados na Tabela 1.

Fazendo-se uma regressão linear dos dados da Tabela 1, para o caso de misturas de óleo de copaíba e óleo de soja obtém-se o valor de 77,8 para o coeficiente linear, que deve ser comparado com o valor 81,4 obtido experimentalmente para o óleo de copaíba. O valor obtido para o coeficiente angular , - 0,78, também apresenta uma boa concordância com o valor da expressão (IAs - IAc)/100, calculado a partir dos dados de IAs e IAc da Tabela 1 , que é igual a $-0,81$. $\mathrm{O}$ valor encontrado para o coeficiente de correlação foi de 0,990 .

Fazendo-se uma regressão linear para os dados da Tabela 1 referentes às misturas de óleo de copaíba e álcool etílico obtém-se os valores de 74,7 para interseção e $-0,77$ para o coeficiente angular e coeficiente de correlação de 0,989 .

\section{Índice de éster de misturas óleo de copaíba-óleo de soja e óleo de copaíba-álcool etílico}

Pode-se demonstrar que a relação entre os valores do índice de éster de misturas de óleo de copaíba e óleo de soja segue a seguinte equação:

$\mathrm{IE}=\mathrm{IEc}+\frac{(\mathrm{IES}-\mathrm{IEc})(\% \mathrm{~S})}{100}$

onde IE representa o índice de éster da mistura óleo de copaíba-óleo de soja e $\% \mathrm{~S}$, a porcentagem de óleo de soja na mistura. IEs e IEc representam os valores do índice de éster dos óleos de soja e de copaíba respectivamente. Pela equação (6), nota-se que deverá haver uma relação linear entre o índice de éster da mistura e o conteúdo de óleo de soja na mesma. Nesta equação IEc representa a interseção da reta com a linha das ordenadas e a expressão (IEs - IEc)/100 representa o coeficiente angular da reta.

No caso das misturas de óleo de copaíba e álcool etílico a relação entre o índice de éster e a concentração de álcool etílico, em partes por cento, é dada pela seguinte equação:

$$
\mathrm{IE}=\mathrm{IEc}+\frac{(\mathrm{IEa}-\mathrm{IEc})(\% \mathrm{~A})}{100}
$$

IE representa o índice de éster de uma mistura de óleo de copaíba e álcool etílico, IEc e IEa representam os índices de éster do óleo de copaíba e álcool etílico, respectivamente e \% A indica a porcentagem de álcool etílico na mistura.
Na Tabela 2 são mostrados os valores do índice de éster obtidos experimentalmente, de misturas de composição variável de óleo de copaíba e óleo de soja e de misturas de óleo de copaíba e álcool etílico.Com estes dados foi possível testar a validade das equações (6) e (7).

Fazendo-se a regressão linear dos dados obtidos no caso de misturas de óleo de copaíba e óleo de soja obteve-se o valor de 14,07 para a interseção, 1,55 para o coeficiente angular e um coeficiente de correlação de 0,997 .

A regressão linear no caso de misturas de óleo de copaíba e álcool etílico forneceu o valor de 18,53 para a interseção da reta, de $-0,21$ para o coeficiente angular e 0,949 para o coeficiente de correlação.

\section{Aplicação dos índices de acidez e de éster a algumas amostras comerciais de óleo de copaíba}

A seguir foram determinados os valores dos índices de acidez e de éster de 8 amostras comerciais de óleo de copaíba, uma amostra de óleo de copaíba obtida in natura para referência e uma amostra de óleo de soja. A finalidade destas determinações consistiu em testar a validade de nossas propostas, isto é, o uso dos índices de acidez e de éster, isoladamente ou em combinação com outros testes, para detectar ou mesmo avaliar o grau aproximado de adulteração do referido produto.

Na Figura 1 são apresentados os valores dos índices de acidez obtidos para as amostras consideradas. Neste caso observa-se que a amostra autêntica, designada $\mathrm{R}$ e as amostras comerciais designadas C1, C2, C6, C7, e C8 apresentam índices de acidez variando ente 80 a $90 \mathrm{mg} \mathrm{KOH}$ por grama de óleo. Como os ensaios cromatográficos ${ }^{1}$ e termogravimétricos ${ }^{6}$ não detectaram adulterações nas referida amostras admite-se que amostras autênticas de óleo de copaíba apresentem valores para o índice de acidez compreendidos entre $80 \mathrm{e}$ 90 miligramas de $\mathrm{KOH}$ por grama de óleo.

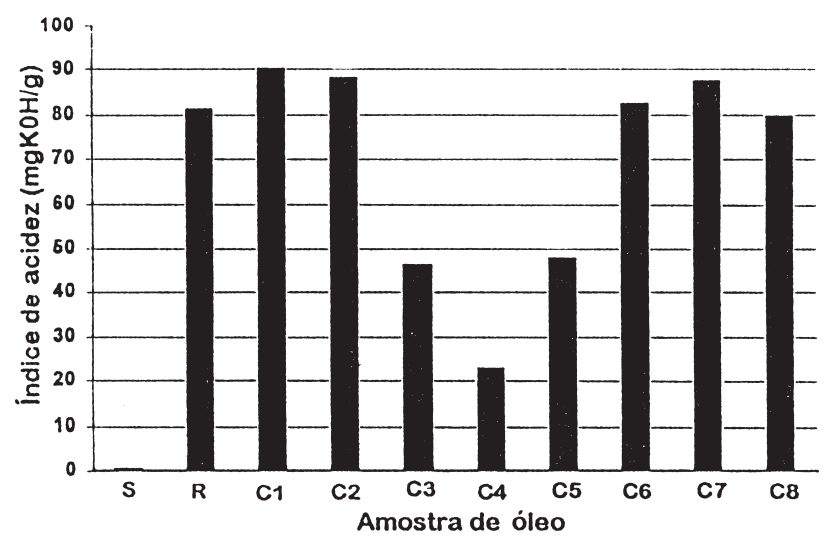

Figura 1. Valores do índice de acidez de algumas amostras de óleo. $R$; amostra de óleo de copaíba obtido in natura; $S$ - amostra de óleo de soja; C1 a C8-amostras comerciais de óleo de copaiba

Por outro lado, como pode ser visto na Figura 1, as amostras designadas C3, C4 e C5 apresentaram valores para o índice de acidez bem abaixo de 80 e portanto devem estar adulteradas. Os valores encontrados para índice de acidez das amostras C3,C4, e C5 foram respectivamente de 46,5, 23,2 e 48,0 mg de KOH/g de óleo. A partir destes valores, utilizando-se a equação (3), foi possível calcular os valores aproximados dos teores de adulterante nas referidas amostras. Chegou-se aos seguintes valores para porcentagem de 
adulterante: $45 \%$ para o caso da amostra $\mathrm{C} 3,73 \%$ para a amostra $\mathrm{C} 4$ e $44 \%$ para C5.

O índice de acidez permite saber se o óleo foi adulterado, assim como avaliar o valor aproximado do teor de adulterante presente. Entretanto, este parâmetro não fornece nenhuma informação a respeito da natureza do adulterante.

Na Figura 2 são mostrados os valores do índice de éster das mesmas amostras com as mesmas designações apresentadas na Figura 1. Observa-se que as amostras C3, C4 e C5 apresentam valores para o índice de éster abaixo de 23, o que indica, de acordo com o nosso critério, que o contaminante das mesmas não deve ser óleo graxo. A ausência de óleo graxo foi comprovada por métodos instrumentais envolvendo a cromatografia ${ }^{1}$ e a termogravimetria ${ }^{6}$. De acordo com os resultados das aplicações destas técnicas o contaminante da amostra C4 foi identificado como sendo óleo mineral. Em relação aos contaminantes das amostras $\mathrm{C} 3$ e $\mathrm{C} 5$, os resultados da termogravimetria sugeriram tratar-se de um material volátil, como é o caso do álcool etílico. É possível calcular, para fins de ilustração, os valores esperados para o índice de éster das referidas amostras, admitindo-se que o contaminante fosse óleo graxo e os teores de contaminante fossem aqueles obtidos através dos valores do índice de acidez. Neste caso, os valores esperados para os índices de éster das amostras C3, C4 e C5, seriam 90, 130 e 87, respectivamente. É possível concluir com segurança que os adulterantes das amostras C3, C4 e C5 não devem ser constituídos de óleo graxo.

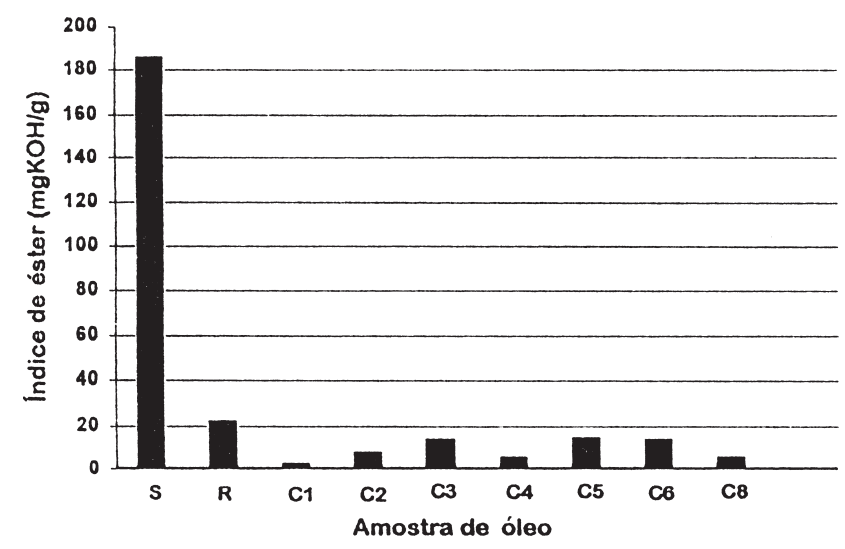

Figura 2. Valores de índice de éster de algumas amostras de óleo. R-amostra de óleo de copaíba obtido in natura. S-amostra de óleo de soja; $C 1$ a C8 amostras comerciais de óleo de copaíba

Um critério proposto para detectar a presença de óleo graxo no óleo de copaíba constitui-se no teste da solubilidade da amostra em álcool absoluto ${ }^{4}$. A insolubilidade parcial da amostra em etanol indicaria a presença de óleo graxo na mesma. As amostras C3 e C5 se mostraram totalmente solúveis em álcool absoluto, o que indicaria a ausência de óleo graxo nas mesmas e está coerente com as conclusões obtidas através do método por nós proposto. Entretanto, a amostra $\mathrm{C} 4$ mostrou-se apenas parcialmente solúvel no referido solvente, o que indicaria que o adulterante fosse constituído de óleo graxo. Esta conclusão está em desacordo com aquela obtida através do nosso método e de alguns métodos instrumentais. Desta maneira, conclui-se que não se pode tomar o teste da solubilidade da amostra em etanol como conclusivo da presença da presença de óleo graxo na amostra. Entretanto, este é um teste simples que pode ser útil se usado em conjunto com o método proposto neste trabalho.
É comum entre os vendedores de óleo de copaíba a crença de que amostras de óleo de copaíba mais viscosas e de coloração mais intensa são as menos passíveis de terem sido adulteradas. De acordo com nossas observações, estes critérios não devem ser empregados como critério de autenticidade do referido material. Observou-se que amostras autênticas de óleo de copaíba podem apresentar uma grande variação de tonalidade e intensidade de cor. Por outro lado, constatou-se que, enquanto as amostras adulteradas não apresentaram valores do coeficiente de viscosidade discrepantes das autênticas, a amostra designada C7,que é uma amostra autêntica, apresentou um valor anormalmente alto em relação às demais. Na realidade acredita-se que o aumento da viscosidade de certas amostras de óleo de copaíba deve ser atribuído à formação de resinas provenientes da oxidação de terpenos em virtude da exposição à luz ou mesmo eventual exposição ao ar ${ }^{1,7,8}$. Como a amostra C7 era a única armazenada em frasco transparente, a influência da luz pode explicar o aumento da viscosidade da mesma.

\section{CONCLUSÃO}

Neste trabalho mostrou-se que o chamado índice de acidez da amostra pode ser usado para se detectar adulterações do óleo de copaíba. Assim sendo, estabeleceu-se que um valor abaixo de 80 $\mathrm{mgKOH} / \mathrm{g}$ para este índice serve como indício de que a amostra foi adulterada. Além disso, o valor do índice de acidez pode ser usado para se avaliar o teor do contaminante na amostra.

Mostrou-se também que, uma vez comprovada a adulteração da amostra do óleo de copaíba através do valor do índice de acidez, o valor do índice de éster da mesma pode fornecer informações a respeito da natureza do contaminante. Assim sendo, estabeleceu-se que um valor deste índice acima de $23 \mathrm{mgKOH} / \mathrm{g}$ indicaria que o contaminante é óleo graxo e um valor abaixo deste limite indicaria que o contaminante é um material não saponificável como etanol ou óleo mineral, por exemplo.

A determinação do índice de acidez de oito amostras comerciais de óleo de copaíba mostrou que três delas sofreram adulterações grosseiras. Por outro lado, o valor do índice de éster das amostras contaminadas mostrou que, em nenhum dos casos o adulterante era óleo graxo. Estas conclusões estão coerentes com aquelas obtidas por técnicas mais sofisticadas como a cromatografia ${ }^{1}$ ou termogravimetria ${ }^{6}$.

Certamente que os valores limite de $80 \mathrm{mgKOH} / \mathrm{g}$ para o índice de acidez e de $23 \mathrm{mgKOH} / \mathrm{g}$ para o índice de éster podem ser melhorados em função de um estudo mais abrangente envolvendo outras espécies do gênero Copaifera. Entretanto, os mesmos se mostraram adequados para a detecção e o cálculo aproximado do teor de adulterante em amostras comerciais de óleo de copaíba.

\section{REFERÊNCIAS}

1. Veiga Jr., V. F.; Patitucci, M. L.; Pinto, A. C.; Quim. Nova 1997, $20,612$.

2. Fernandes, R. M.; Pereira, N. A.; Paulo, L. G.; Rev. Bras. Farm. 1992, 73, 53.

3. Opdyke, D. L. J.; Food. Cosm. Toxicol. 1976, 14 Suppl. II, 687.

4. Correa Pio, M.; Dicionário das Plantas Úteis do Brasil e das Exóticas Cultivadas, Ministério da Agricultura: Rio de Janeiro, 1931, p. 371.

5. Moretto, E.; Fett, R.; Óleos e Gorduras Vegetais (Processamento e Análises), Editora da UFSC: Florianópolis, 1989, p. 142.

6. Vasconcelos, A. F. F.; Godinho, O. E. S.; An. Assoc. Bras. Quim. 2001, 50, 192.

7. Costa, M.; Tanaka, M. A.; Imamura, P. M.; Marsaioli, A.J.; Phytochemistry 1999, 50, 117.

8. Champetier, G.; Monnerie, L.; Introducion a la Química Molecular, EspasaCalpe S.A.: Madrid,1973. 